\title{
A Review of Wind Speed Estimation for Wind Turbine Systems Based on Kalman Filter Technique
}

\author{
M. Najafi Khoshrodi ${ }^{1}$, Mohammad Jannati ${ }^{2}$, Tole Sutikno ${ }^{3}$ \\ ${ }^{1}$ Golestan Electrical Power Distribution Company \\ ${ }^{2}$ UTM-PROTON Future Drive Laboratory, Faculty of Electrical Engineering, Universiti Teknologi Malaysia, \\ 81310 Skudai, Johor Bahru, Malaysia \\ ${ }^{3}$ Department of Electrical Engineering, Universitas Ahmad Dahlan, Yogyakarta, Indonesia
}

\begin{tabular}{|c|c|}
\hline Article Info & ABSTRACT \\
\hline & \multirow{6}{*}{$\begin{array}{l}\text { This paper presents a review of wind speed estimation based on Kalman } \\
\text { filter technique applied to wind turbine systems. Generally, wind speed } \\
\text { measurement is performed by anemometer. The wind speed provided by the } \\
\text { anemometer is measured at a single point of the rotor plane which is not the } \\
\text { accurate wind speed. Also, using anemometer increases the system cost, } \\
\text { maintenance, complexity and reduces the reliability. For these reasons, } \\
\text { estimation of wind speed is needed for wind turbine systems. In this paper, } \\
\text { the several wind speed estimation methods based on Kalman filter method } \\
\text { used for wind turbine systems are reviewed. }\end{array}$} \\
\hline Received Mar 3, 2016 & \\
\hline Revised May 15, 2016 & \\
\hline Accepted May 30, 2016 & \\
\hline Keyword: & \\
\hline Kalman Filter & \\
\hline
\end{tabular}

Review

Speed Estimation

Wind Turbine

Copyright (C) 2016 Institute of Advanced Engineering and Science. All rights reserved.

Corresponding Author:

M. Najafi Khoshrodi,

Golestan Electrical Power Distribution Company.

Email: mnajafikhoshrodi92@gmail.com

\section{INTRODUCTION}

Wind energy is playing a significant role in future energy scene. About $10 \%$ electricity can be supplied by the wind energy by the year 2020. Wind energy is one the fastest increasing and environment friendly renewable energy sources. Wind turbines convert the kinetic energy of the wind to electrical energy [1]-[5].

Generally, wind turbines are categorized into two types, fixed and variable speed wind turbines which variable speed wind turbine is more reliable. To control the variable speed wind turbines, the measurement of wind speed is required. For this, anemometers are placed to measure the wind speed. Wind turbine anemometer cannot measure the exact shift area wind speed. Moreover, using anemometer increases the overall cost, size and reduces the reliability of the system. Another disadvantage of using anemometer is that the cost and maintenance of the anemometer is high. In this case, the sensorless strategies can guarantee the performance of control system. In the literature, several speed estimation techniques are reported as an alternative method for anemometers [6]-[39]. These techniques are based on Kalman filter [9]-[24], neural network [25]-[27], adaptive neuro fuzzy inference systems [28]-[30], extreme learning machine [31], [32], support vector machine [33], [34] and etc [35]-[39].

Concerning the estimation of the speed, there have been a number of researches that presented different techniques for this purpose. While the estimation technique based on observer approximately depends to the accuracy of the model; the Kalman filter is one of the most general model based estimator [8]. The Kalman filter algorithm introduced by R. E. Kalman represents an efficient method for the recursive data processing. 
The main contribution of this research is to review the presented techniques for wind speed estimation based on Kalman filter method. Based on this, in this paper, several numbers of good publications have reported the wind speed estimation methods applied for wind turbine systems are discussed. The paper is organized as follows: After introduction in Section 1, the Kalman filter methodology is presented in Section 2. Section 3 discusses the different methods of speed estimation based on Kalman filter and finally the paper concludes at Section 4.

\section{KALMAN FILTER}

Kalman filter is the statistically sequential estimation procedure for dynamic systems. Observations are recursively combined with recent forecasts with weights that minimize the corresponding biases. This algorithm can be formulated as following equations [40], [41].

$$
\begin{aligned}
& x_{t}=F_{t} \cdot x_{t-1}+w_{t} \\
& y_{t}=H_{t} \cdot x_{t}+v_{t} \\
& x_{t / t-1}=F_{t} \cdot x_{t-1} \\
& P_{t / t-1}=F_{t} \cdot P_{t-1} \cdot F_{t}^{\mathrm{T}}+W_{t} \\
& x_{t}=x_{t / t-1}+K_{t}\left(y_{t}-H_{t} \cdot x_{t / t-1}\right) \\
& K_{t}=P_{t / t-1} \cdot H_{t}^{T}\left(H_{t} \cdot P_{t / t-1} \cdot H_{t}^{T}+V_{t}\right)^{-1} \\
& P_{t}=\left(I-K_{t} \cdot H_{t}\right) P_{t / t-1}
\end{aligned}
$$

\section{WIND SPEED ESTIMATION BASED ON KALMAN FILTER}

In the literature, different techniques for wind speed estimation based on Kalman filter including linear, extended and unscented and etc. Kalman filter, have been presented. In Ref. [10], a hybrid Kalman filter-artificial neural network model was proposed based on an Auto-Regressive Integrated Moving Average (ARIMA) model to further improve the forecasting accuracy of wind speed. The framework of the study used in [10] is shown in Figure 1.

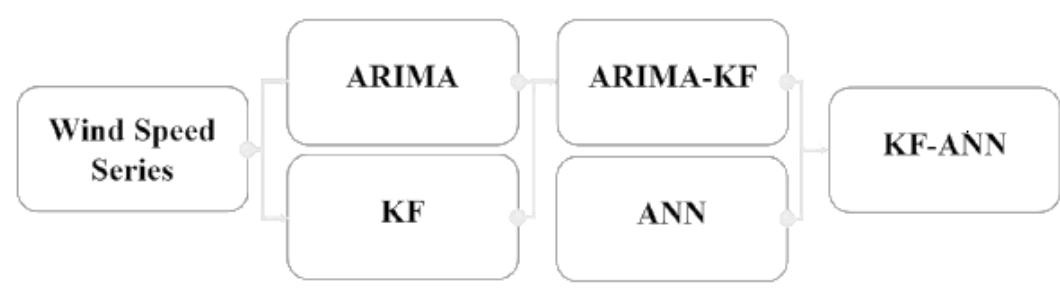

Figure 1. The framework of the study used in [10]

In [11] the comparison between Kalman filter and Takagi-Sugeno observer methods for wind speed estimation has been presented. In this paper, the Kalman filter and Takagi-Sugeno observer techniques are compared based on reduced-order models of a reference wind turbine with different modelling details. In [12], unscented Kalman filter is incorporated with Support Vector Regression (SVR) based state-space model in order to accurately update the short-term estimation of wind speed sequence. In the presented method, support vector regression is used to formulate a nonlinear state-space model and then unscented Kalman filter is adopted to achieve dynamic state estimation. Schematic diagram of the used SVR-unscented Kalman filter method for wind speed estimation is shown in Figure 2. 


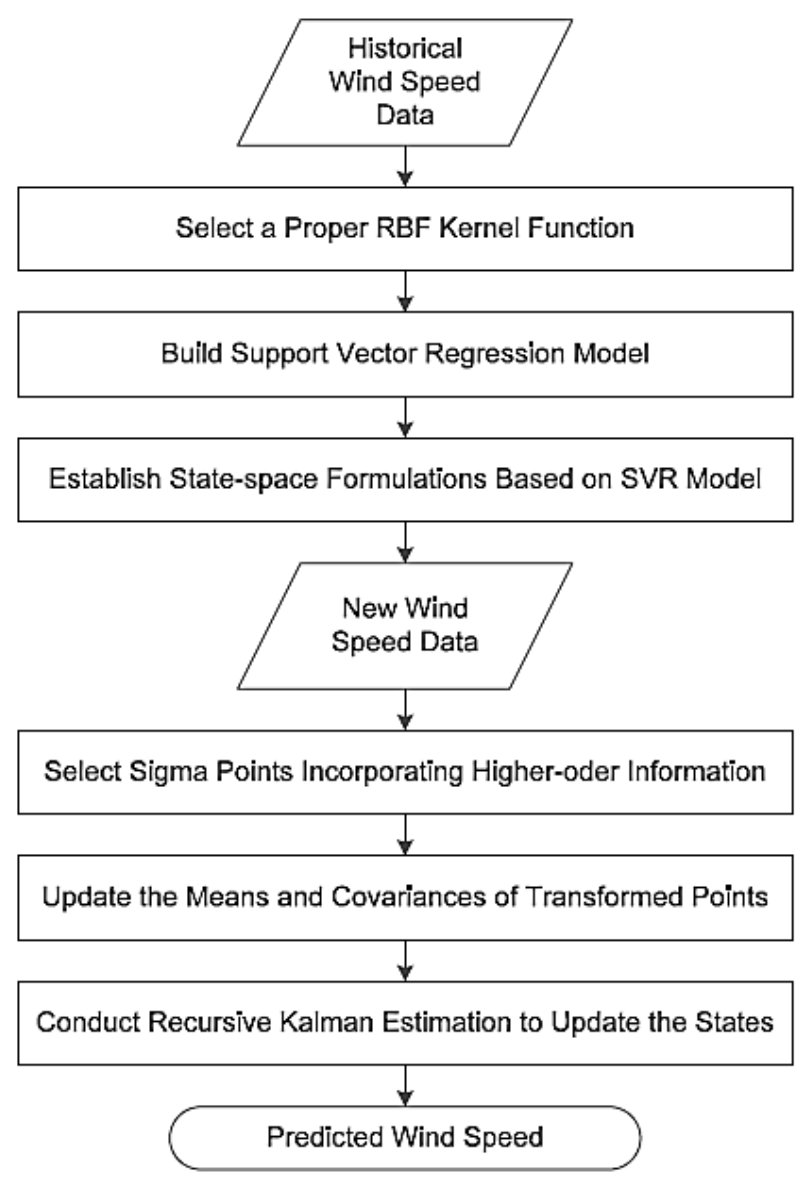

Figure 2. Schematic diagram of the SVR-unscented Kalman filter method for wind speed estimation [12]

In [13], a method for wind power prediction has been proposed using physical and statistical modeling. In [13], the Kalman and Kolmogorov-Zurbenko filters, have been used to adopt local area characteristics and to eliminate possible systematic errors. In [14], an adaptive Kalman filter has been developed and applied to 2-metre temperature and 10-metre wind-speed forecasts in Iceland. The presented method consists of adding two strategies to the conventional Kalman filter algorithm that adaptively estimate the noise statistics individually.

In [15], a comparison of three one-step-ahead forecasting techniques for wind speed data based on robust Kalman filtering has been presented. The author showed that the weighted robust Kalman filter [42] and robust statistics Kalman filter [43] yield better performances than the standard Kalman filter and the thresholded Kalman filter [44] in terms of the sample skewness, sample kurtosis and residual error.

In [17], two hybrid methods (hybrid ARIMA-artificial neural network model and hybrid ARIMAKalman model) for wind speed prediction have been proposed and their performances have been compared. The framework of the proposed hybrid models used in [17] is shown in Figure 3.

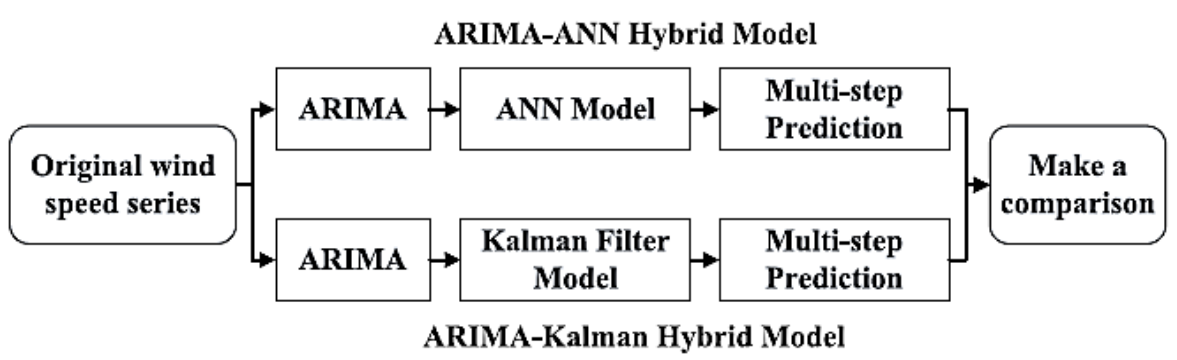

Figure 3. The framework of the proposed hybrid models in [17] 
Paper [18] presented a technique for the estimation of the wind speed in order to be used for the control of a variable speed stall regulated wind turbine. The algorithm in [18] consists of a Kalman filter for estimation of states such as rotor speed and Newton-Raphson method for estimation of wind speed (see Figure 4). In this paper, the Kalman filter is improved with adaptive algorithms that estimate the unknown covariances of the process and measurement noises.

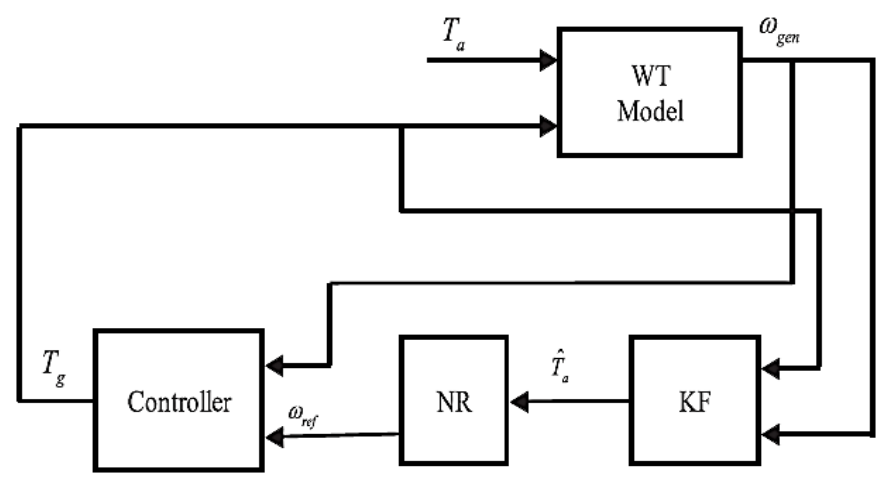

Figure 4. Control scheme used in [18]

In Ref. [19] rotational speed reference is determined by aerodynamic torque estimation using Kalman filter. Adaptive optimal fuzzy system for rotational speed control is presented basis of mechanical and electrical parts of wind turbine equations.

In [21] two mass model based estimation of effective wind speed have been proposed. In this paper the generator torque as shown in Figure 5 is controlled with nonlinear static and dynamic state feedback. The estimator used is the Kalman filter.

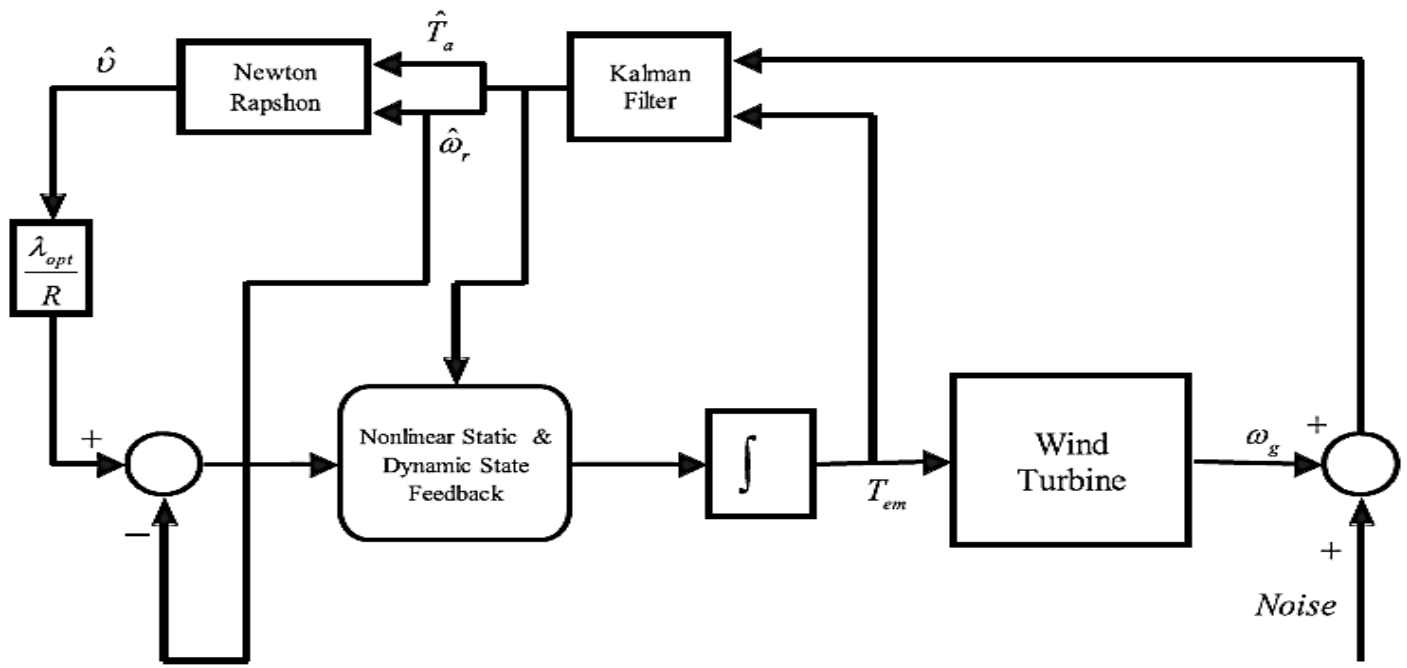

Figure 5. Control scheme used in [21]

In [22], a Higher Order Wavelet Neural Network (HOWNN) trained with an extended Kalman filter is proposed to solve the wind forecasting problem. In this paper, a Kalman filter algorithm is used to update the synaptic weights of the wavelet network. In paper [23], wind turbine state and parameter based on a dual Kalman filter theory have been estimated. The dual Kalman filter scheme is shown in Figure 6. The results in [23] show that the wind speed and rotor speed in below and above rated wind speed can be estimated with a high quality. 


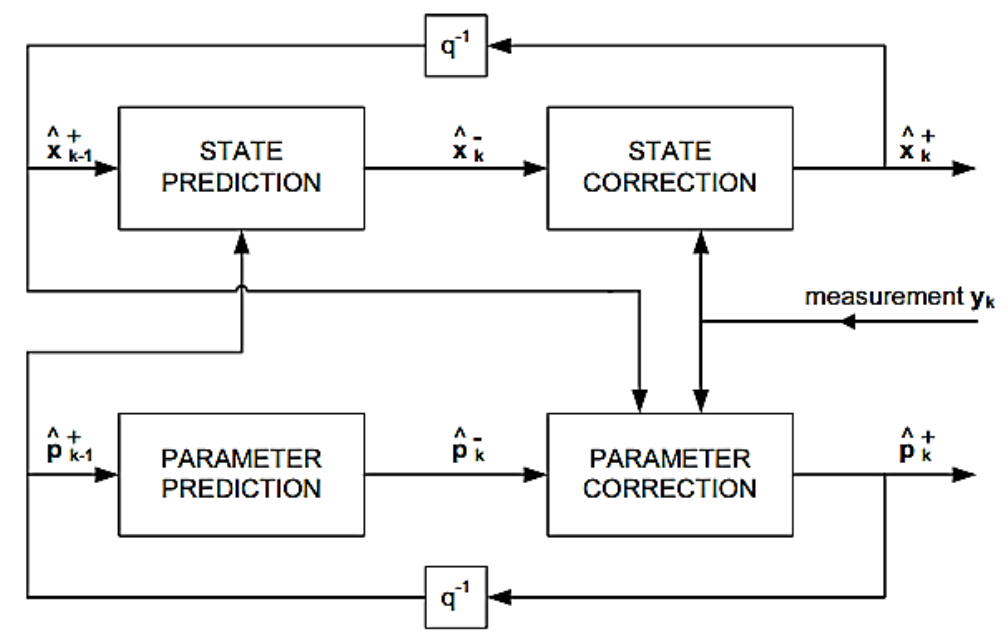

Figure 6. Dual Kalman filter scheme [23]

\section{CONCLUSION}

To control the variable speed wind turbines, the wind speed measurement is required. Normally, the wind speed provided by the anemometer. Using anemometer increases the system cost, maintenance, complexity and reduces the reliability. Accurate wind speed estimation found to be useful in terms of growth in energy capture. In this research, a review has been done on the effective estimation of wind speed. Practically all the important wind speed estimation techniques based on Kalman filter applied to wind turbines have been carefully discussed.

\section{REFERENCES}

[1] G. M. Joselin Herbert, et al., "A review of wind energy technologies," Renewable and sustainable energy Reviews, vol. 11, pp. 1117-1145, 2007.

[2] A. K. Sharma, "Study of wind turbine based seig under balanced/unbalanced loads and excitation," International Journal of Electrical and Computer Engineering, vol. 2, pp. 353-370, 2012.

[3] Y. Zheng, et al., "Mode Analysis of Horizontal Axis Wind Turbine Blades," TELKOMNIKA Indonesian Journal of Electrical Engineering, vol. 12, pp. 1212-1216, 2014.

[4] H. Li, et al., "Fault-tolerant control for current sensors of doubly fed induction generators based on an improved fault detection method," Measurement, vol. 47, pp. 929-937, 2014.

[5] E. Sesto and C. Casale, "Exploitation of wind as an energy source to meet the world's electricity demand," Journal of Wind Engineering and Industrial Aerodynamics, vol. 74, pp. 375-387, 1998.

[6] M. N. Soltani, et al., "Estimation of rotor effective wind speed: A comparison," IEEE Transactions on Control Systems Technology, vol. 21, pp. 1155-1167, 2013.

[7] K. Z. Østergaard, et al., "Estimation of effective wind speed," In Journal of Physics: Conference Series, vol. 75, pp. 012082, 2007.

[8] T. Burton, et al., "Energy Handbook," John Wiley \& Sons, 2011.

[9] H. Babazadeh, et al., "An hour ahead wind speed prediction by Kalman filter," In Power Electronics and Machines in Wind Applications (PEMWA), pp. 1-6, 2012.

[10] O. B. Shukur and M. H. Lee, "Daily wind speed forecasting through hybrid KF-ANN model based on ARIMA," Renewable Energy, vol. 76, pp. 637-647, 2015.

[11] E. Gauterin, et al., "Effective wind speed estimation: Comparison between Kalman Filter and Takagi-Sugeno observer techniques," ISA transactions, 2015.

[12] K. Chen and J. Yu, "Short-term wind speed prediction using an unscented Kalman filter based state-space support vector regression approach," Applied Energy, vol. 113, pp. 690-705, 2014.

[13] C. Stathopoulos, et al., "Wind power prediction based on numerical and statistical models," Journal of Wind Engineering and Industrial Aerodynamics, vol. 112, pp. 25-38, 2013.

[14] P. Crochet, "Adaptive Kalman filtering of 2-metre temperature and 10-metre wind-speed forecasts in Iceland," Meteorological Applications, vol. 11, pp. 173-187, 2004.

[15] C. D. Zuluaga, et al., "Short-term wind speed prediction based on robust Kalman filtering: An experimental comparison," Applied Energy, vol. 156, pp. 321-330, 2015.

[16] F. Cassola and M. Burlando, "Wind speed and wind energy forecast through Kalman filtering of Numerical Weather Prediction model output," Applied energy, vol. 99, pp. 154-166, 2012. 
[17] H. Liu, et al., "Comparison of two new ARIMA-ANN and ARIMA-Kalman hybrid methods for wind speed prediction," Applied Energy, vol. 98, pp. 415-424, 2012.

[18] D. Bourlis and J. A. M. Bleijs, "A wind speed estimation method using adaptive Kalman filtering for a variable speed stall regulated wind turbine," In 11th International Conference on Probabilistic Methods Applied to Power Systems (PMAPS), pp. 89-94, 2010.

[19] Z. Xin-fang, et al., "Adaptive optimal fuzzy control for variable speed fixed pitch wind turbines," In Fifth World Congress on Intelligent Control and Automation (WCICA), pp. 2481-2485, 2004.

[20] H. Vihriälä, "Control of variable speed wind turbines (PhD thesis)," Tampere University of technology, 2002.

[21] B. Boukhezzar and H. Siguerdidjane, "Nonlinear control of a variable-speed wind turbine using a two-mass model," IEEE Transactions on Energy Conversion, vol. 26, pp. 149-162, 2011.

[22] L. J. Ricalde, et al., "Higher order wavelet neural networks with Kalman learning for wind speed forecasting," In Symposium on Computational Intelligence Applications In Smart Grid (CIASG), pp. 1-6, 2011.

[23] P. Mateljak, et al., "Dual kalman estimation of wind turbine states and parameters," In Proceedings of the International Conference on Process Control, pp. 85-91, 2011.

[24] D. Jena and S. Rajendran, "A review of estimation of effective wind speed based control of wind turbines," Renewable and Sustainable Energy Reviews, vol. 43, pp. 1046-1062, 2015.

[25] H. Li, et al., "Neural-network-based sensorless maximum wind energy capture with compensated power coefficient," IEEE Transactions on Industry Applications, vol. 41, pp. 1548-1556, 2005.

[26] O. Barambones, et al., "A neural network based wind speed estimator for a wind turbine control," In 15th IEEE Mediterranean Electrotechnical Conference (MELECON), pp. 1383-1388, 2010.

[27] F. Jaramillo-Lopez, et al., "A novel online training neural network-based algorithm for wind speed estimation and adaptive control of PMSG wind turbine system for maximum power extraction," Renewable Energy, vol. 86, pp. 38-48, 2016.

[28] D. Petković, et al., "Generalized adaptive neuro-fuzzy based method for wind speed distribution prediction," Flow Measurement and Instrumentation, vol. 43, pp. 47-52, 2015.

[29] S. Shamshirband, et al., "Sensorless estimation of wind speed by adaptive neuro-fuzzy methodology," International Journal of Electrical Power \& Energy Systems, vol. 62, pp. 490-495, 2014.

[30] E. T. Al-Shammari, et al., "Estimation of wind turbine wake effect by adaptive neuro-fuzzy approach," Flow Measurement and Instrumentation, vol. 45, pp. 1-6, 2015.

[31] S. Wu, et al., "Extreme learning machine based wind speed estimation and sensorless control for wind turbine power generation system," Neurocomputing, vol. 102, pp. 163-175, 2013.

[32] G. B. Huang, et al., "Extreme learning machine: theory and applications," Neurocomputing, vol. 70, pp. 489-501, 2006.

[33] X. Kong, et al., "Wind speed prediction using reduced support vector machines with feature selection," Neurocomputing, vol. 169, pp. 449-456, 2015.

[34] D. Liu, et al., "Short-term wind speed forecasting using wavelet transform and support vector machines optimized by genetic algorithm," Renewable Energy, vol. 62, pp. 592-597, 2014.

[35] W. Qiao., "Echo-state-network-based real-time wind speed estimation for wind power generation," In International Joint Conference on Neural Networks (IJCNN), pp. 2572-2579, 2009.

[36] H. Liu, et al., "An EMD-recursive ARIMA method to predict wind speed for railway strong wind warning system," Journal of Wind Engineering and Industrial Aerodynamics, vol. 141, pp. 27-38, 2015.

[37] L. Tian, et al., "A Gaussian RBF network based wind speed estimation algorithm for maximum power point tracking," Energy Procedia, vol. 12, pp. 828-836, 2011.

[38] E. Erdem and J. Shi, "ARMA based approaches for forecasting the tuple of wind speed and direction," Applied Energy, vol. 88, pp. 1405-1414, 2011.

[39] R. G. Kavasseri and K. Seetharaman, "Day-ahead wind speed forecasting using f-ARIMA models," Renewable Energy, vol. 34, pp. 1388-1393, 2009.

[40] R. E. Kalman, "A new approach to linear filtering and prediction problems," Journal of basic Engineering, vol. 82, pp. $35-45,1960$.

[41] P. Louka, et al., "Improvements in wind speed forecasts for wind power prediction purposes using Kalman filtering," Journal of Wind Engineering and Industrial Aerodynamics, vol. 96, pp. 2348-2362, 2008.

[42] J. A. Ting, et al., "A Kalman filter for robust outlier detection," In IEEE/RSJ International Conference on Intelligent Robots and Systems, pp. 1514-1519, 2007.

[43] T. Cipra and R. Romera, "Kalman filter with outliers and missing observations," Test, vol. 6, pp. 379-395, 1997.

[44] I. C. Schick and S. K. Mitter, "Robust recursive estimation in the presence of heavy-tailed observation noise," The Annals of Statistics, pp. 1045-1080, 1994. 